
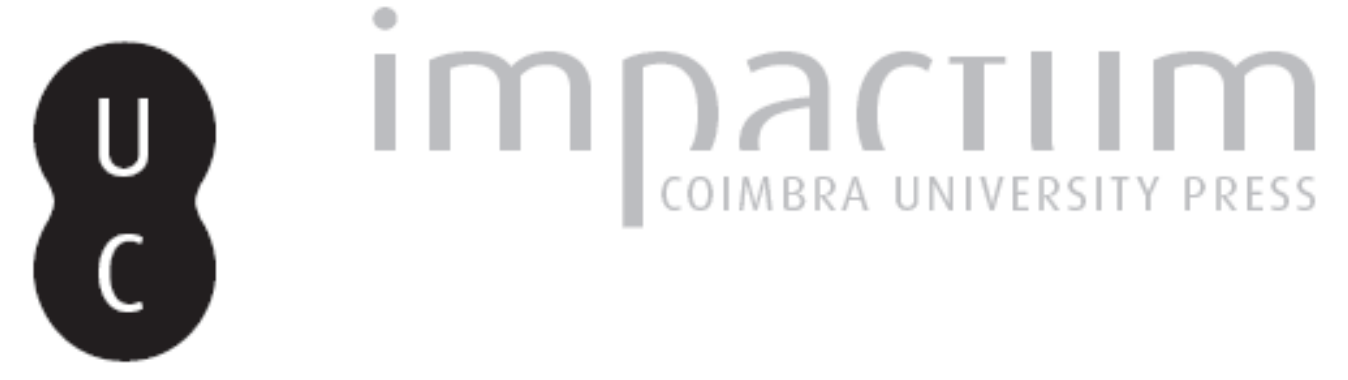

\title{
Prevenção de inundações e reabilitação de edifícios em zonas inundáveis
}

Autor(es): Rocha, João Soromenho

Publicado por: Associação Portuguesa de Riscos, Prevenção e Segurança

URL persistente:

URI:http://hdl.handle.net/10316.2/40176

DOI:

DOI:https://doi.org/10.14195/1647-7723_2_2

Accessed : $\quad$ 26-Apr-2023 11:40:38

A navegação consulta e descarregamento dos títulos inseridos nas Bibliotecas Digitais UC Digitalis, UC Pombalina e UC Impactum, pressupõem a aceitação plena e sem reservas dos Termos e Condições de Uso destas Bibliotecas Digitais, disponíveis em https://digitalis.uc.pt/pt-pt/termos.

Conforme exposto nos referidos Termos e Condições de Uso, o descarregamento de títulos de acesso restrito requer uma licença válida de autorização devendo o utilizador aceder ao(s) documento(s) a partir de um endereço de IP da instituição detentora da supramencionada licença.

Ao utilizador é apenas permitido o descarregamento para uso pessoal, pelo que o emprego do(s) título(s) descarregado(s) para outro fim, designadamente comercial, carece de autorização do respetivo autor ou editor da obra.

Na medida em que todas as obras da UC Digitalis se encontram protegidas pelo Código do Direito de Autor e Direitos Conexos e demais legislação aplicável, toda a cópia, parcial ou total, deste documento, nos casos em que é legalmente admitida, deverá conter ou fazer-se acompanhar por este aviso.

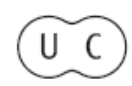




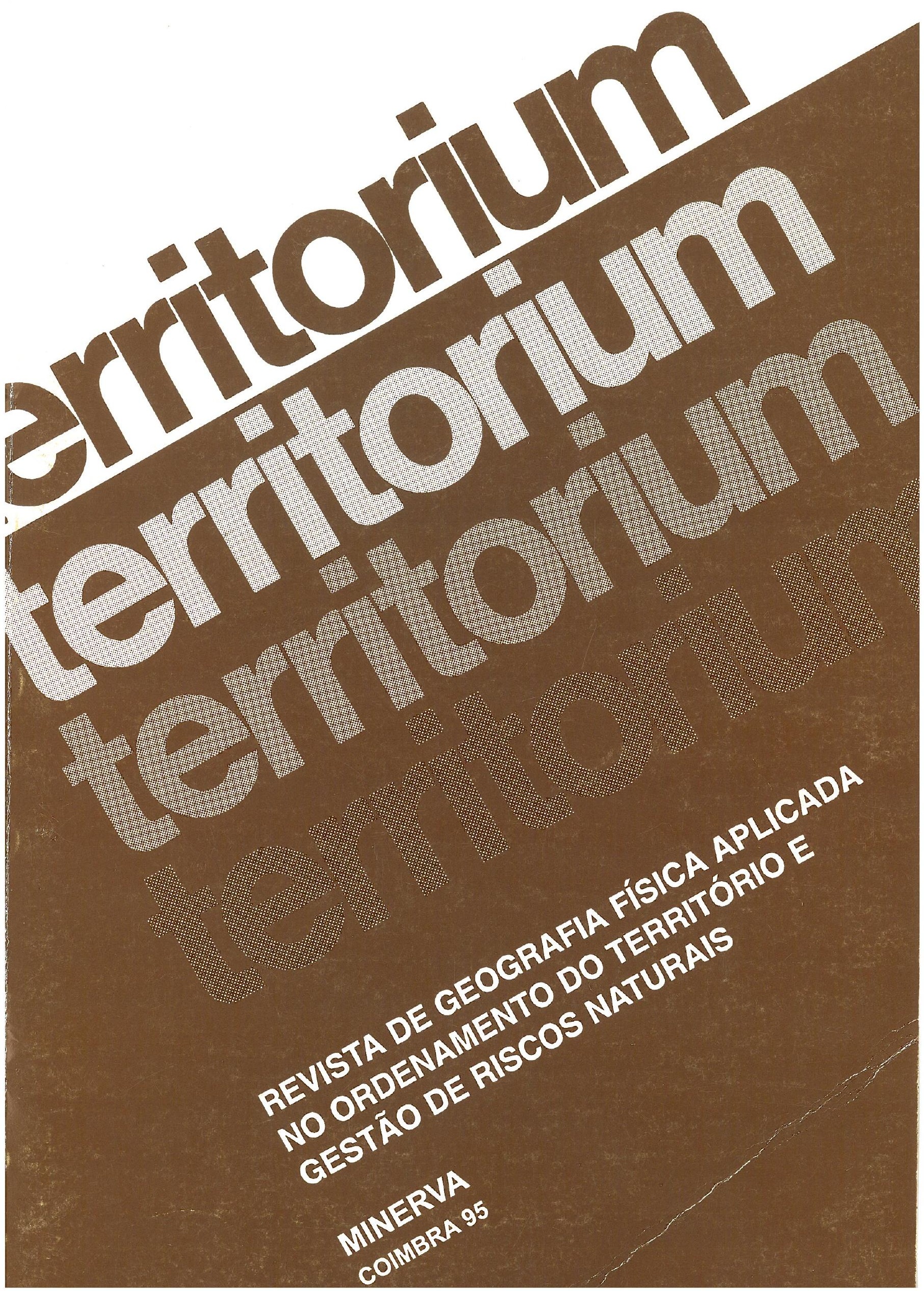




\title{
Prevenção de inundações e reabilitação de edifícios em zonas inundáveis
}

\author{
João Soromenho Rocha*
}

\begin{abstract}
Resumo:
Depois de se definirem os conceitos fundamentais em jogo e de se apresentarem as causas das inundações, caracterizam-se as zonas inundáveis e os principais tipos de danos causados aos edifícios. Trata-se, finalmente, da reabilitação dos edifícios atingidos, bem como das medidas que minimizem as reabilitações, dando prioridade à prevenção e exemplificando com casos portugueses.

Palavras chave:

Inundação, riscos de inundação, prevenção, reabilitação de edifícios.
\end{abstract}

Résumé:

Après la définition des notions fondamentalles en jeu et la présentation des causes des inondations, on caractérise les zones inondables et les types principaux de dégâts provoqués sur les bâtiments. Toujours avec des cas d'études au Portugal, l'auteur discute enfin la réhabilitation des bâtiments atteints, aussi bien que les mesures minimisant les réhabilitations, en donnant priorité à la prévention.

Mots clés:

Inondation, risque d'inondation, prévention, réhabilitation de bâtiments.

\begin{abstract}
:
After defining the major concepts in discussion and introducing the causes of floods, the Author explains the characteristics of flooding areas and the most important types of flood damages suffered by buildings. Finally, exemplifying with portuguese case studies, he explains the housing rehabilitation and the measures which can be taken to minimise its necessity, with priority to prevention.

Key words:

Floods, flood risk, prevention, building rehabilitation.
\end{abstract}

\section{Conceitos fundamentais}

Oconceito de inundação é intuitivo e está associado à acção de cobrir de água uma determinada superfície, de alagar, de espalhar água sobre uma área. No entanto, em termos técnicos, é indispensável caracterizar além da acção de inundar a origem da quantidade de água que provoca esta inundação. Se a origem da inundação for uma ruptura de uma conduta de alimentação estar-se-á em presença de uma inundação facilmente caracterizável e dominável. Se a origem da inundação for somente a quantidade de água que se precipita directamente, na área inundada, durante um fenómeno de pluviosidade atmosférica, está-se perante um fenómeno de deficiente drenagem local. Se a origem da inundação for a quantidade de água proveniente da arrebentação das ondas do mar está-

\footnotetext{
* Engenheiro. Investigador Coordenador do Laboratório Nacional de Engenharia Civil (LNEC).
}

se perante um fenómeno localizado na costa. Mas as grandes inundações são originadas pelos transbordamentos dos rios, durante a ocorrência de cheias.

O conceito de cheia está associado à ocorrência de um valor muito elevado de caudal num curso de água, resultante da ocorrência de precipitação intensa. Quando a cheia provoca o transbordamento do leito normal, dá-se a inundação de terrenos marginais. Leito normal corresponde ao que vulgarmente se designa por leito menor, com capacidade para o escoamento de caudais de cheia, que em média ocorrem todos os anos. Leito de cheia corresponde ao que vulgarmente se designa por leito maior, com capacidade para o escoamento de caudais de cheia com apreciáveis períodos de retorno, 10 a 100 anos. Acima deste período de retorno, a cheia corresponde a uma grande catástrofe.

O período de retorno, $\mathrm{T}$, de um dado caudal, é o valor médio do número de anos que decorre para que este caudal seja excedido. Designa-se por risco, R, a probabilidade de um dado caudal ser excedido uma 
ou mais vezes durante um determinado período de tempo. Sendo assim $R=1-(1 / T)^{\mathrm{N}}$.

A bacia hidrográfica de um curso de água numa dada secção é a área topográfica sobre a qual a queda de precipitação origina o escoamento nessa secção. Quando nãoé explícita, a secção de referência coincide com a foz.

A dimensão da bacia hidrográfica é importante para a caracterização das cheias e das inundações. Nos pequenos cursos de água, com tempos de resposta de poucas horas, as cheias são repentinas. Bastante mais em bacias urbanas do que em bacias rurais. À medida que a área da bacia vai aumentando, a resposta vai sendo mais lenta, sendo a subida da água durante a inundação também lenta.

As disciplinas que estudam as inundações são fundamentalmente a hidrologia, em que se caracterizam as relações precipitação-caudal, e a hidráulica, em que se caracterizam as relações caudal-altura de água. Também necessária deveria ser a da engenharia civil, de âmbito estrutural, na definição das acções de forças hidrodinâmicas nas estruturas sujeitas a inundações e respectivas soluções estruturais. Complementarmente, na análise global dos problemas das inundações, dever-se-ão incluir as disciplinas de planeamento e de urbanismo, as de economia, macro e microeconomia, e a sociologia.

É patente o carácter multidisciplinar deste problema e a não consideração das várias disciplinas referidas poderá certamente conduzir a soluções imperfeitas, só detectadas posteriormente, conduzindo ànecessidade de onerosas reabilitações.

Faz-se notar que as inundações fluviais constituem um dos riscos naturais mais importantes da superfície terrestre, causando grandes danos e muitas milhares de vítimas por ano na Terra.

\section{Causas das inundações}

A ocorrência de cheias é determinada fundamentalmente pelas condições meteorológicas das bacias hidrográficas, sendo os seus efeitos em grande parte determinados pela intervenção humana nas bacias hidrográficas.

A causa primeira das cheias é a ocorrência de precipitação em grande quantidade sobre as bacias hidrográficas, sob a forma de chuva e aguaceiros, que origina escoamento superficial e caudais elevados nos cursos de água. Estas cheias, nas proximidades de estuários, sofrem também a influência dos níveis de maré e do estado de agitação marítima. A ocorrência de precipitação está frequentemente associada à passagem de superfícies frontais e de depressões.

As situações meteorológicas associadas à ocorrência de cheias, em grandes bacias hidrográficas, são determinadas pela passagem de repetidos sistemas frontais, originando períodos de tempo chuvoso relativamente longos. São exemplos as cheias de 1978, Fevereiro-Março, em que passaram 13 sistemas frontais em 18 dias, bem como as de 1979, Fevereiro, causando grandes inundações nas margens dos rios Douro, Mondego e Tejo.

Pelo contrário, nas pequenas bacias, as cheias podem ser ocasionadas por apenas uma depressão. São exemplos as cheias nas bacias da região de Lisboa, em 1967 e em 1983, ambas em Novembro.

As características geomorfológicas e fisiográficas das bacias hidrográficas condicionam o fenómeno das cheias de duas formas. Primeiramente, na separação da precipitação total em infil tração e em precipitação útil, ou escoamento superficial. Em segundo lugar, influenciando o tempo de resposta da bacia e de propagação da cheia. Relativamente menores cheias ocorrem em bacias mais permeáveis, ou com maior cobertura vegetal. Cheias mais rápidas ocorrem em bacias mais inclinadas.

O mesmo caudal de cheia pode ocasionar diferentes alturas de escoamento, e diferentes velocidades da água, consoante as características hidráulicas dos leitos. Como foi referido, o leito normal comporta as pequenas cheias. Para este leito, caracterizado hidraulicamente pelas suas dimensões (largura e profundidade), pela sua inclinação longitudinal, pela sua rugosidade, e pela sua forma, a maiores inclinações correspondem maiores velocidades e menores profundidades. No entanto, na maioria dos casos de inundações, os problemas estão no leito maior. Neste leito, caracterizado pelos mesmos parâmetros acima referidos para o leito menor, o problema é hidraulicamente semelhante, mas a direcção do escoamento é mais livre, podendo haver escoamento, perpendicular às margens, resultante do efeito do transbordamento do rio, paralelo às margens numa situação de cheia estabilizada, ou na maioria dos casos com escoamentos complexos resultantes da grande variabilidade geométrica destes leitos, em geral com muitos obstáculos.

A actividade humana nas bacias hidrográficas condiciona de forma intencional ou descuidada a ocorrência de cheias e inundações. Todas as obras de aproveitamento hidráulico, para fins de abastecimento público, de produção de electricidade ou para rega, em que se construa uma barragem de média a grande dimensão, desempenham um papel importante na propagação das cheias. Também há barragens construídas com o objectivo explícito de controlar as cheias. Mas todas as albufeiras, que se formam a montante da barragem, têm a possibilidade de atenuar as cheias, e por consequência, diminuir as inundações, a jusante das mesmas. É óbvio que na zona da albufeira, zonas nunca inundadas passam a estar nessas condições permanentemente. É um custo a analisar.

Mas, também é necessário estar ciente que todas as barragens têm um risco, muitíssimo pequeno se 
forem construídas com as adequadas regras de engenharia, de ao ruir provocar uma catastrófica onda de cheia repentina, muito maior do que qualquer cheia natural. Ou com muito mais frequência, de por mau funcionamento dos órgãos de descarga, provocarem maiores cheias do que as naturais.

De uma maneira muito mais difusa, ao longo de toda a bacia hidrográfica, a intervenção da actividade humana, alterando as características morfológicas, de cobertura vegetal e de permeabilidade do solo, provoca efeitos não desprezáveis na ocorrência das cheias. Casos significativos são o do desflorestamento, e ainda mais, a passagem de uma bacia rural a urbana, em que a maior quantidade de água por escoamento superficial pode ser da ordem das várias dezenas em percentagem.

A urbanização dos vales inundáveis é, todavia, o grande problema das inundações. Desde sempre estas zonas inundáveis apresentam uma grande atracção para o desenvolvimento da habitação. Desde sempre, as sociedades, que aí desenvolvem a sua actividade, estão cientes dos riscos de inundação e a eles se adaptam. Uma das intervenções mais antigas, por ser relativamente fácil, é a da construção de diques longitudinais de defesa. Embora sejam eficientes para as pequenas cheias, anulando totalmente as inundações frequentes, para as grandes cheias deixam de actuar, por os diques serem transbordados, criando com a sua ruptura situações de grande perigo.

Em climas mediterrâneos, como em grande parte do território português, em que períodos de seca são alternados com períodos de grande pluviosidade, a ocupação das margens dos pequenos leitos tem sido por vezes totalmente inconsciente, causando verdadeiras catástrofes. Os melhores exemplos podem ser encontrados nas bacias envolventes a Lisboa. Nas cheias de 1967 morreram centenas de pessoas devido a estas circunstâncias. Mais recentemente problemas semelhantes são encontrados na orla litoral do Algarve, e um pouco por todo o país nas novas urbanizações, em que a condicionante inundação não foi considerada.

A gestão da ocupação do solo, nas imediações das linhas de água, necessita actualmente, mais de que outrora, já que a experiência de ocupação habitual foi perdida ou desprezada pelos técnicos e decisores, de elementos que ajudem à decisão da ocupação do solo atendendo às zonas de risco de inundação.

\section{Caracterização das zonas inundáveis}

Oconhecimento rigoroso das cheias, e consequentes inundações em locais susceptíveis ao transbordamento das linhas de água, naturais ou corrigidas pelo homem, deve ser considerado como um elemento indispensável a uma grande variedade de actividades técnicas de engenharia e urbanística, incluindo o importante sector do alojamento.

Torna-se pois compreensível a necessidade de dispor de métodos fiáveis para a simulação dos processos físicos de transformação da precipitação em escoamento nos cursos de água. Obtido o primeiro dado essencial, o caudal de cheia de projecto, ao qual está associada uma probabilidade de ocorrência pré determinada pelo autor do estudo, ou da obra, aquele caudal é utilizado, por sua vez, num modelo de simulação hidráulica, que transforme caudais em níveis. Este tipo de modelo matemático de regolfo, isto é, escoamento em regime permanente, é relativamente simples, sendo utilizável por qualquer projectista.

A obtenção dos dados necessários aos dois tipos de modelos, hidrológicos e hidráulicos, embora não sendo complexa, é trabalhosa, mas sê-lo-á cada vez menos com o avanço dos meios informáticos.

Não basta dispor de modelos reconhecidamente bons para se garantirem bons resultados. Estes dependem grandemente da qualidade dos dados e de uma ajustada calibração. A calibração do modelo hidrológico é feita com base na simulação de um determinado número de acontecimentos de cheia, sendo em geral suficiente seleccionar cerca de 5 ocorrências representativas.

A calibração conjunta dos modelos hidrológicos e dos modelos hidráulicos é geralmente complicada pelo facto de não se dispor de registos de níveis. No entanto, é sempre possível o conhecimento de marcas de cheia, marcas físicas em estruturas marginais, ou na maioria dos casos através de informação verbal dos habitantes locais.

Os resultados obtidos com a utilização destes modelos caracterizam muito bem as zonas inundáveis. De um modo simples podem ser enumerados os seguintes parâmetros para cada uma das secções, e para cada caudal de cálculo, em que se divide um trecho do rioem estudo: número da secção, profundidade máxima do escoamento, cota da superfície livre da água, cota da linha de energia, cota do escoamento em regime crítico, perda de carga, altura cinética média, caudal no leito menor, caudal no leito maior esquerdo, caudal no leito maior direito, áreas nestes leitos, volume de água acumulada desde a primeira secção, área de inundação referida até à primeira secção, tempo de escoamento desde a primeira secção, velocidades médias nas referidas partes da secção, largura total do escoamento, etc.

Todos estes elementos permitem caracterizar numericamente a inundação para cada caudal, associado a cada período de retorno, e desenhar os perfis transversais, longitudinal e, principalmente, as plantas com as zonas inundáveis. No quadro seguinte apresentase uma síntese das inundações num troço da ribeira da Laje, junto a Algueirão - Mem Martins. 


\begin{tabular}{|c|c|c|c|c|c|c|}
\hline \multirow{3}{*}{$\begin{array}{c}\text { Período } \\
\text { de retorno } \\
\text { (ano) }\end{array}$} & \multirow{3}{*}{$\begin{array}{l}\text { Caudal } \\
\left(\mathrm{m}^{3} / \mathrm{s}\right)\end{array}$} & \multirow{3}{*}{$\begin{array}{c}\text { Superficie } \\
\text { inundada } \\
\left(\times 10^{3} \mathrm{~m}^{2}\right)\end{array}$} & \multirow{3}{*}{$\begin{array}{c}\text { Volume } \\
\text { de água } \\
\left(\times 10^{3} \mathrm{~m}^{3}\right)\end{array}$} & \multirow{3}{*}{$\begin{array}{c}\text { Altura } \\
\text { média } \\
(\mathrm{m})\end{array}$} & \multicolumn{2}{|c|}{ Caudal (m3/s) } \\
\hline & & & & & Superfície & Em pressão \\
\hline & & & & & \multicolumn{2}{|c|}{ na ponte da secção 14.3B } \\
\hline 5 & 28 & 32 & 35 & 1,09 & 6 & 22 \\
\hline 20 & 40 & 37 & 50 & 1,35 & 11 & 29 \\
\hline 100 & 54 & 40 & 65 & 1,63 & 18 & 36 \\
\hline 500 & 67 & 42 & 77 & 1,83 & 25 & 42 \\
\hline PMP & 108 & 45 & 107 & 2,37 & 52 & 56 \\
\hline
\end{tabular}

Este exemplo, extraído de um dos estudos efectuados (J. ROCHA, 1987), também chama a atenção para os obstáculos que, em certas condições, constituem as pontes. Se estas não estiverem bem dimensionadas podem ou ser simplesmente galgadas, cortando o tráfego, ou destruídas. No quadro, mostra-se que a ponte é galgada para caudais de cheia de 5 anos, passando $22 \mathrm{~m}^{3} / \mathrm{s}$ no vão da ponte, e galgando-a os restantes $6 \mathrm{~m}^{3} / \mathrm{s}$. O termo PMP (Precipitação Máxima Possível) designa uma condição limite considerada fisicamente possível.

A legislação prevê a delimitação, caso a caso, das áreas inundáveis, que designa por zonas adjacentes, subdivididas em áreas de ocupação edificada proibida e condicionada (Dec.-Lei 468/71 e 89/87). Esta classificação foi feita para um reduzido número de casos, mas estão estabelecidas medidas preventivas para as áreas incluídas dentro do limite da maior cheia conhecida ou de uma faixa de $100 \mathrm{~m}$ para cada lado da margem do curso de água, quando se desconheça aquele limite.

A marcação de uma área inundada correspondente a cheia que tem uma probabilidade de ocorrência de uma vez em cem anos, vulgarmente designada "a cheia dos 100 anos" ou "a cheia centenária", é usualmente a que interessa em termos legais de definição de leito de cheia. Pela primeira vez, esta área foi definida para a bacia da ribeira da Laje (Decreto Regulamentar $n^{\circ} 45 / 86$ de 86/09/26, Diário da República, II série, $n^{\circ} 222$ ), com base nos estudos hidrológicos e hidráulicos acima referidos. Na Fig. 1 é apresentado um extracto desta área definida na ribeira da Laje.

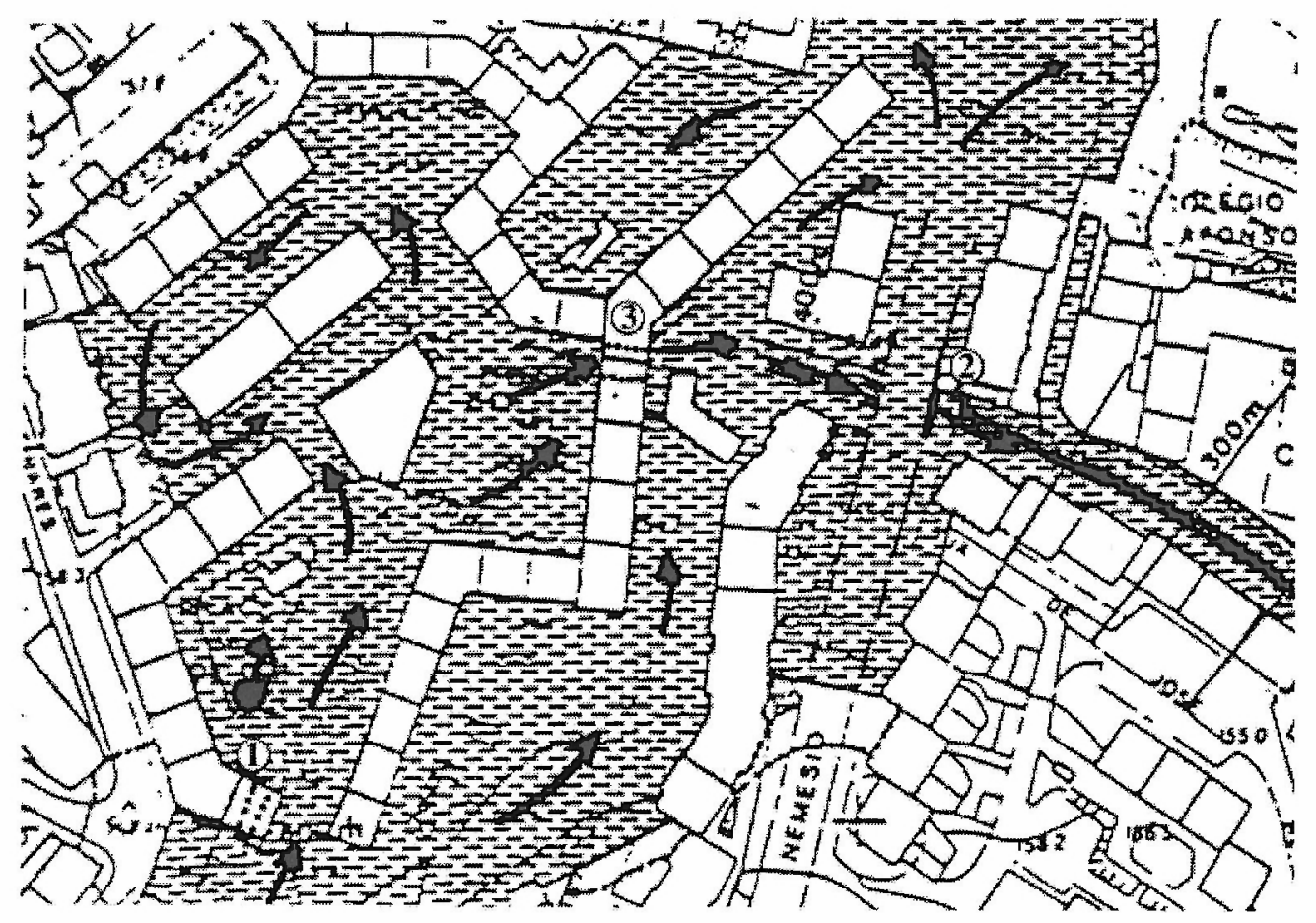

Fig. 1 - Extracto da área da "cheia centenária" da Ribeira da Laje. 
A cartografia de trabalho foi à escala 1/2000. Neste desenho é patente a coexistência indesejável entre as zonas de alojamento e o escoamento em cheia. Situação que em média ocorreria com intervalos de tempo de cerca de 17 anos. Por coincidência as grandes cheias nas pequenas bacias da região de Lisboa ocorreram com um intervalo de 16 anos (1967 e 1983). É muito provável que até ao ano 2000 ocorram cheias análogas a estas duas nesta região.

$\mathrm{Na}$ figura, estão marcados com setas o sentido do escoamento sobre os passeios e arruamentos. Neste local, a ribeira da Laje passa enterrada desde a extremidade inferior esquerda, passando sob um edifício, só voltando a correr livremente no ponto 2 , a jusante de uma ponte. Houve uma ruptura do tecto da ribeira canalizada no ponto 1. Por sorte o edifício assinalado com 3 tinha uma abertura para peões que deu escoamento à água de inundação. Se não existisse esta abertura, a altura máxima da água, em vez de chegar a poucos centímetros do parapeito das janelas do rés-do-chao, poderia inundar totalmente esse piso, visto que o escoamento ficaria totalmente confinado pelos edifícios. Esta situação de confinação existiu, por exemplo, em Cascais, na mesma data.

A responsabilidade na definição das áreas inundáveis é repartida por muitas entidades. Julga-se que tal co-responsabilidade é desejável, não sendo necessário procurar centralizar numa única entidade esta tarefa. Mas deverá certamente haver uma entidade que conheça tudo o que for sendo feito nessa matéria.

Nos projectos de aproveitamentos hidráulicos, quer nas fases de plano geral, quer principalmente na fase de projecto, foram desde sempre automaticamente contemplados os aspectos de definição de caudais de cheia de projecto e níveis de inundação, somente na secção da estrutura a construir, nas imediações das estruturas ou em trechos compridos de rio. Pode-se afirmar que nas últimas 4 décadas foi sendo acumulada informação sobre as cheias suficiente para localizar grande número de áreas de inundação. Mais haveria se o país tivesse regulamentação mais adequada para a definição das condicionantes de ordem hidráulica para qualquer construção de obra junto a linhas de água, especialmente para as urbanizações.

Aproveitando esta informação dispersa pelo país, e para contemplar as preocupações do Serviço Nacional de Protecção Civil, está em curso, no LNEC, um estudo sobre a caracterização das zonas de risco de inundação em Portugal. No relatório de análise preliminar foi preparada uma carta à escala $1 / 500000$ com a localização destas zonas de risco. Na fase subsequente estão a ser preparadas cartas à escala $1 / 50000$ e 1/100000 para as bacias dos rios Sado, Tejo e Douro e seus afluentes. Para chegar à definição adequada à intervenção no alojamento, a escalas de 1/2000 ou maiores será indispensável a actuação das autarquias. No âmbito do trabalho para o SNPC vai ser feito um inquérito às autarquias com problemas de inundações de modo a considerar a experiência local no que diz respeito a este tema. Por exemplo, é óbvio que os Planos Directores Municipais considerem este aspecto.

Podem ser designados alguns concelhos com problemas de inundação em zonas urbanizadas, sem preocupação de incluir todos os que terão estes problemas. São eles de norte para sul: Monção, Valença, Ponte de Lima, Viana do Castelo, Barcelos, Esposende, Vila do Conde, Peso da Régua, Porto, Vila Nova de Gaia, Torre de Moncorvo, Mirandela, Chaves, vários no vale dos rios Vouga e Mondego, Leiria, Torres Vedras, Sintra, Cascais, Oeiras, Amadora, Loures, Vila Franca de Xira, Alenquer, Belmonte, Covilhã, Fundão, vários no vale do rio Tejo, Setúbal, Alcácer do Sal e vários no litoral algarvio.

A elaboração de análises de pormenor deverá ser feita localmente e demorará certamente vários anos até estar toda a informação de base disponível.

\section{Danos de inundação}

A avaliação económica dos danos causados pelas inundações deve ser um dos principais elementos a ter em conta nas decisões sobre a gestão deste risco. De facto, as restrições devidas às inundações são cada vez mais fortes porque os danos têm sempre tendência a aumentar, os financiamentos disponíveis são limitados e os custos da gestão são cada vez maiores por ser cada vez mais necessário garantir as compatibilidades intersectoriais nomeadamente com a inclusão de problemas ambientais, políticose sociais, em suma maior participação pública.

As inundações provocam danos com uma grande diversidade, tanto nos aspectos físicos, como nos aspectos económicos. Em particular podem ser referidos os danos sobre as pessoas, os danos materiais da habitação (imobiliário, mobiliário, veículos), os danos no comércio, nos serviços, na indústria, na administração, nas redes, nas infra-estruturas, nos equipamentos públicos, os impactos secundários de todos os anteriores, os custos do socorroe das intervençōes nas emergências.

Numa classificação económica dos danos podem serreferidos os binómios, impactos directos/indirectos, tangíveis/intangíveis, potenciais/reais e ainda os impactos da existência do risco.

Exemplificando no que diz respeito ao alojamento, o impacto directo num edifício é materializado com o contacto físico da água no mesmo. Tal contacto pode danificar o revestimento, pode danificar os acessórios do edifício e pode danificar o seu conteúdo, móveis, bens armazenados, instalações di versas. Entre os impactos indirectos podem-se distinguir os impactos primários da zona inundada dos impactos secundários sofrido pelas zonas exteriores. A determinação destes 
impactos indirectos é bastante difícil, já que o prejuízo num local pode ser globalmente compensado pelo benefício no outro local. Haverá transferência de fornecedores por exemplo.

Os impactos tangíveis podem ser medidos e avaliados directamente em termos económicos. Os intangíveis são muito mais dificilmente avaliados economicamente, tais como as perdas de vidas humanas, os problemas de saúde, a angústia, as rupturas do modo de vida, o isolamento, as lembranças e os patrimónios cultural e histórico.

Cada um dos impactos nas pessoas, nos bens, nas actividades pode ser ligado a um ou mais parâmetros hidráulicos característicos do fenómeno de inundação, ou da submersão da área considerada. Estes parâmetros condicionam a importância dos danos em ligação com os parâmetros que caracterizam as pessoas e os bens atingidos. Os parâmetros principais para este efeito são:

- profundidade da água;

- duração da submersão;

- velocidade da corrente;

- velocidade da subida da superfície da água;

- materiais transportados no escoamento (lodos, poluentes);

- materiais flutuantes (incluindo automóveis);

- estação do ano.

Na prática os mais utilizados são a profundidade e a duração, não sendo em muitos casos desprezável os materiais transportados pelo escoamento em cheia.

A determinação do valor dos danos pode ser feita fundamentalmente de dois modos: avaliação por acontecimento isolado e avaliação do custo médio anual dos danos. Em geral, o segundo necessita de avaliação do custo de um ou mais acontecimentos. Esta avaliação, para a qual não vão ser descritos os métodos utilizados, pode atender, consoante as possibilidades, aos aspectos estáticos ou dinâmicos, aspectos determinísticos ou estatísticos, distribuição espacial e temporal, eàs unidades elementares geográfica e económica. Exemplos de células elementares geográficas são as parcelas de terreno, os quarteirões urbanos e as unidades de recenseamento. Exemplos de unidades económicas eque devem estar interligadas com as anteriores, são os custo $/ \mathrm{m}^{2}$, custo/unidade. custo/m de profundidade, etc.

No Grupo de Trabalho Sobre as Causas das Cheias Ocorridas em Novembro de 1983 na Área Metropolitana foi feita uma avaliação económica dos danos das inundações na ribeira das Vinhas, em Cascais. Posteriormente na DGRN foi feita também uma avaliação para a ribeira da Laje, em AlgueirãoMem Martins e em Oeiras, neste caso com a colaboração do Flood Hazard Research Center do Middlesex Polytechnic, com um modelo designado ESTDAM. Em ambos os casos os problemas principais são os urbanos. No projecto da Regularização Fluvial e de Controle das Cheias da ribeira da Meimoa (Beira Baixa) também foram avaliados os danos resultantes das inundações, principalmente agrícolas.

$\mathrm{Na}$ prática, há quatro relações fundamentais para a avaliação dos prejuízos causados pelas inundações:

- caudal - frequência;

- caudal - área inundada;

- área inundada - danos;

- danos - frequência.

O custo médio anual das inundações é a esperança matemática dada pela integração da última curva.

As intervenções de reabilitação e de prevenção em zonas inundáveis devem ter em conta estes dados económicos, com os quais é possível avaliar em termos de benefício-custo várias alternativas de solução.

Reabilitação de edifícios em zonas inundadas

A reabilitação de edifícios pressupõe que estes edifícios já foram inundados. A primeira questão que se deve pôr diz respeito às causas desta inundação. Será que esta inundação estava prevista, ou será que nunca tinha sido considerado tal hipótese? Infelizmente, pelo que se conhece, é mais provável o segundo motivo.

Em geral, quanto às habitações mais antigas é provável que não sejam inundáveis. Com excepção das que estão implantadas nas franjas dos grandes vales aluvionares, nos quais se verificam fenómenos de assoreamento geral durante os últimos séculos. Mas neste caso as cheias são de subida lenta, e os fenómenos de assoreamento são muito lentos. Exemplo paradigmático pode ser visto na Igreja de Santa Cruz, de Coimbra. Foi construída no século XII, certamente ao abrigo das cheias importantes. Cerca do ano de 1540 as cheias ficavam 4 degraus abaixo da laje da Igreja. Cerca de 1786 as cheias ficavam ao nível dessa laje, enquanto que meio século depois já era necessário descer um degrau para entrar na Igreja. Antes das actuais obras era preciso descer 7 degraus. Em números aproximados, durante os últimos 400 anos o fundo do rio Monde go terá assoreado cerca de $1,7 \mathrm{~m}$. O mesmo fenómeno de assoreamento ocorreu nos vales dos rios Lima, Vouga, Tejo e Sado. Em menor escala, o mesmo fenómeno é verificado nos pequenos vales aluvionares.

Mas os grandes problemas parecem estar nas urbanizações mais recentes, dos anos $50 \mathrm{em}$ diante, nos vales dos pequenos rios. Nestes vales, com maiores inclinações e a corrente de água com muitos materiais transportados, as inundações apresentam grande poder destrutivo. Na região de Lisboa, em 1967 morreram mais de 500 pessoas e em 1983 o número de mortes foi da ordem de uma dezena. O menor número de mortes da última cheia, dever-se-ácertamenteà memória que muitas pessoas guardavam 
da catástrofe anterior. Em 1967 infelizmente não havia nem memória porque a maioria dos novos habitantes eram migrantes, nem tinha havido estudo técnico adequado. No entanto, em 1983 foi enorme o número de casas destruídas, cerca de 610 . Foi estimado em 12 milhões de contos o prejuízo total de bens materiais desta cheia (DGRN, 1987).

. Conhecidos os efeitos das cheias, em cada local, a sua reabilitação deveráser feita tendo em consideração todos os aspectos referidos anteriormente. Tarefa difícil e demorada, principalmente, se não for designado um chefe de equipa experiente com capacidade e meios financeiros suficientes. Esta metodologia foi seguida depois das cheias de 1983 , na região de Lisboa, embora o Grupo formado não tivesse todas as características requeridas. O que foi conseguido não foi, no entanto, desprezível.

Diagnosticadas as causas dos danos nos edifícios, a reabilitação terá de conjugar as medidas de reconstrução, demolição e de prevenção. Se o risco de nova inundação for suficientemente elevado, ou se o custo da reconstrução for proibitivo comparado com o futuro dano médio anual, a demolição será certamente a solução adequada.

Se o risco de inundação for considerado aceitável a reconstrução deverá ser feita atendendo às boas regras de construção para esse local, materiais resistentes à acção da água, reforço da estrutura para resistir às acções hidrodinâmicas, defesa local à volta do edifício ou nas entradas e aberturas do edifício. Dois casos que podem ser considerados muito prováveis são, respectivamente, a inutilização de caves ou de pisos no rés-do-chão, ou a alteração do tipo de ocupação, por exemplo, de alojamento para armazém de materiais não deterioráveis pela água.

A reabilitação mais urgente, ou medidas imediatas, pode ser composta pelos seguintes aspectos:

- identificação de obras de emergência;

- levantamento dos dados hidráulicos e económicos da última e recente inundação;

- definição de normas dedicadas à área acidentada;

- acompanhamento das soluções de reabilitação;

- preparação dos elementos para as medidas de médio prazo, ou de prevenção.

A identificação de obras de emergência deverá ser feita o mais cedo possível, logo após a passagem da cheia, e será feita com base numa apreciação local, mediante visita pormenorizada a toda a zona. Designará as estruturas a demolir por serem manifestamente perigosas, definirá as intervenções nos leitos das linhas, se ficarem obstruídos com entulhos ou assoreados com aluviões, e definirá a estratégia global de limpeza de detritos. Nesta fase de emergência é essencial incluir na equipa de intervenção, especialistas nas técnicas de construção civil, na hidráulica fluvial e nas infra-estruturas. Eventualmente serão encomen- dados estudos de gabinete com prazos de execução muito curtos, da ordem da semana. Deverá ser considerada a hipótese de ocorrência de nova cheia, mesmo que seja de pequena intensidade,

Imediatamente a seguir deverão ser constituídas equipas de campo com o objectivo de fazer o levantamento rigoroso das zonas inundadas, marcando em cartas, e nas estruturas existentes na zona inundada, as cotas máximas da água, e sempre que possível a descrição da variação dessas cotas durante a cheia, com base no relato dos que a ela assistiram. Este trabalho será rigoroso se por coincidência houver limnígrafos na zona. Simultaneamente será feito um levantamento económico dos danos, com o duplo interesse de caracterização dessa cheia e das eventuais indemnizações.

Com os dados acima referidos, deverá ser possível, nas primeiras semanas a seguir à inundação, definir algumas normas dedicadas à área acidentada. Nomeadamente, interdição de reconstrução de edificações derrubadas, interdição de qualquer alteração nalgumas zonas, imposição de estudos hidráulicos de pormenor a qualquer projecto de obra na zona inundada e solicitação aos donos das obras transversais ou marginais (pontes e diques) de estudos técnicos sobre a capacidade de vazão ou de interferência no escoamento em cheia.

A necessidade de impor normas dedicadas à zona inundada resulta da ausência regulamentar das condicionantes hidráulicas na construção civil. Existem regulamentos que contemplam a acção dos sismos e do vento. Para a acção hidrodinâmica do escoamento fluvial, principalmente, em cheia, há um vazio regulamentar.

Enquanto não existir regulamento, torna-se imperioso que ao menos nas zonas acidentadas sejam implementadas medidas locais que garantam qualidade aos projectos. O objectivo é a execução de um estudo técnico, para qualquer construção ou urbanização implantada junto às linhas de água de qualquer dimensão, que contenha os seguintes elementos, definidos para as condições anteriores e posteriores:

a) caracterização geomorfológica e de ocupação da bacia hidrográfica da linha de água que passa pela área em estudo;

b) determinação dos caudais de cheia, pelo menos, para os períodos de retorno de 5,20,50 e 100 anos, utilizando modelos hidrológicos precipitação-escoamento, calibrados pelo menos para uma ocorrência observada, e pelo menos para uma secção transversal representativa, devendo sê-lo para mais secções sempre que a dimensão do projecto o justificar;

c) determinação das alturas de água nas linhas de água e respectivos leitos de cheia, para os mesmos períodos de retorno, nos troços abrangidos 
pelo projecto, recorrendo a modelos inatemáticos de cálculo de regolfo e incluindo ainda o cálculo do escoamento em secções singulares, tais como pontes, canalizações, estreitamentos, descarregadores frontais e laterais, etc., devendo ser efectuada uma calibração, pelo menos, para uma ocorrência observada;

d) caracterização da constituição do leito da linha de água e verificação da capacidade de mobilização do seu fundo para os vários caudais de cheia acima referidos, bem como a caracterização das fontes de sedimentos provenientes da bacia hidrográfica e transportados pelas linhas de água em cheia;

e) justificação técnico-económica da solução proposta mostrando nomeadamente que o período de retorno do caudal de projecto escolhido garante a minimização dos custos e danos associados às inundações previstas durante a vida útil média das estruturas a construir, e das estruturas envolventes pre-existentes a jusante e a montante, que se situam na zona de influência hidrológica e hidráulica do projecto em análise.

O que é proposto não é mais do que uma pormenorização das actuais exigências, que apresentam disposições incompletas ou omissas, tornando inapta a garantia dos objectivos previstos nas leis gerais a adequabilidade das obras construídas em leito de cheia na rede de drenagem das linhas de água.

Quando as obras são de pequena envergadura, os estudos solicitados serão relativamente simplificados, e deverá haver a preocupação da Administração Central ou Local em prepararem manuais e regulamentos, nacionais ou municipais, com um conjunto de procedimentos expeditos.

As medidas de médio prazo não são mais do que a prevenção que deve estar devidamente equacionada.

\section{Prevenção em zonas inundáveis}

A prevenção nas zonas de risco de inundação diz fundamentalmente respeito ao ordenamento do território, neste caso condicionado pelo fenómeno cheia - inundação.

As acções a empreender devem resultar de estudos técnico-económicos à escala das bacias hidrográficas. Havendo a necessidade em definir zonas de protecção, não se deve no entanto perder de vista que se esta o for em excesso revela-se fraca, comparada com a natural resistência da sociedade às medidas restritivas. Note-se que em Portugal, devido à forte sazonalidade da precipitação e à grande variabilidade interanual, a tendência natural é a da aproximação das linhas de água, mesmo que estejam fortemente poluídas, facilitando o acesso a uma fonte de água que se torna insignificante durante as longas estiagens.

Por estas razões, é necessário um apreciável esforço dos arquitectos, planeadores e empreendedores para conciliarem interesses naturalmente antagónicos, gerados pela grande diferença entre as secções molhadas que ocorrem por ocasiões de cheia e aquelas que se anulam em grande percentagem dos dias em todos os anos.

A necessidade de habitação conduz a discussões acérrimas sobre a quantidade e a qualidade da mesma. A elaboração de regulamentos e a actuação de entidades de fiscalização que garantam a adequabilidade de cada nova habitação tem sido uma tarefa árdua, com tendência para se agravar à medída que se incluem novas matérias a regulamentar. A regulamentação com o fim de proteger das inundações exigirácertamente uma coesa e firme entidade fiscalizadora.

Nas medidas a médio prazo, o principal é a conciliação entre a solução encontrada por via de estudos técnicos e económicos, baseada numa informação científica, e as prioridades políticas, económicas e culturais.

De qualquer modo, é necessário ter presente que as soluções de tipo estrutural, ou mesmo de zonamento preventivo, são eficientes até um valor de caudal de projecto adequadamente adoptado. A probabilidade de este valor ser ultrapassado no tempo de vida útil de qualquer estrutura é suficientemente significativo para dever ser necessário prever medidas mitigadoras pós-desastres, já que a segurança absoluta não existe.

Atendendo a todas estas razões, são descritas algumas medidas de prevenção consideradas indispensáveis a uma racional intervenção na construção de edifícios em zonas com risco de inundação:

1 - Delimitação em planta cadastral e topográfica das zonas com diferentes valores de risco de inundação e respectivas profundidades, velocidades de escoamento e carga sólida tendo em conta a ocupação existente. Esta medida deverá estar a cargo da administração central, ou das futuras administrações da bacia hidrográfica, para as grandes bacias. Uma delimitação mais expedita deverá haver nos Planos Directores Municipais.

2 - Discussão publica das cartas de risco acima referidas e sua posterior divulgação após eventuais correcções.

3 - Preparação da regulamentação da ocupação permitida nas várias zonas de risco e definição das competências de intervenção (a incorporar na gestão de recursos hídricos e/ou gestão autárquica e/ou gestão de recursos naturais).

4 - Revisão periódica das zonas com riscos de inundação, com base na acumulação de novos dados (por exemplo, de 5 em 5 anos).

5 - Preparação da regulamentação para os projectos de construção em zonas de risco de inundação, incluindo o total da obra, e cada um dos seus 
componentes. No caso dos edifícios, os regulamentos definirão as acções hidrodinâmicas mínimas em função dos parâmetros dos escoamentos das cheias e as características mínimas de vários componentes estruturais, de revestimentos, de materiais e de soluções de implantação adequados para resistir à inundação. Em urbanizações deverão ser contempladas as condicionantes hidráulicas das obras de travessia das linhas de água (pontes e pontões) e das obras de circulação e de parqueamento de veículos. Também serão regulamentadas as soluções de revestimento de margens de linhas de água ef ou dos seus leitos.

6 - Análise das consequências de ocorrência de inundações mais intensas do que as previstas nas cartas de risco e nos projectos efectuados. Faz-se especial referência à existência do Regulamento de Segurança de Barragens (Anexo ao Dec.-Lei No 11/90, D. R. N 5 de 90-01-06) em que se prevê o caso dos acidentes em grandes barragens, os quais podem provocar cheias catastróficas embora com uma probabilidade de ocorrência muito menor do que as cheias consideradas habitualmente. A carta de riscos exigida para estas zonas influenciadas por eventual ruptura de barragens deverão ser elaboradas pelos donos da obra, e os resultados comunicados ao SNPC, sendo de carácter reservado.

7 - Planificação de estratégias de fuga baseada em modelos de previsão em tempo real. Recentemente começou a ser desenvolvida investigação na área da utilização do radar na previsão das cheias, o que permitirá antecipar a previsão.

Quanto às medidas de mitigação podem ser referidas as seguintes:

1 - Preparação de planos de socorro de emergência, contemplando locais de acolhimento prédemarcados, armazenagem de materiais de reabastecimento, etc.

2 - Preparação para a execução de inventariação para a determinação rigorosa das consequências dos danos a ocorrer em futuras inundações.

3 - Definição de esquemas de implementação de fundos de socorro, ou de seguros. Faz-se notar que presentemente as companhias de seguros tem serviços de seguros que contemplam as inundações. Na Norma $n^{\circ}$ 99/86 do Instituto de Seguros de Portugal (D.R. n ${ }^{\circ} 180$, II Série, de 86-08-07), é definida, nas condições gerais, a cobertura do risco de inundações. São garantidos os danos causados aos bens seguros em consequência đe:

“a) Tromba de água ou queda de chuvas torrenciais - precipitação atmosférica de intensidade superior a dez milímetros em dez minutos, no pluviómetro; b) Rebentamento de adutores, colectores, drenos, diques e barragens;

c) Enxurrada ou rebentamento do leito de curso de águas naturais ou artificiais."

No entanto, na definição das condições especiais, ficam excluídas da cobertura as perdas ou danos causados:

“a) Por subidas de maré, marés vivas e, mais genericamente, pela acção do mar e outras superfícies marítimas, naturais ou artificiais;

b) Em construções de reconhecida fragilidade.... $\mathrm{e}$, ainda, quando os edifícios se encontrem em estado de reconhecida degradação...;

c) Em mercadorias ... ao ar livre;

d) Em muros, vedações e portões."

Desconhece-se o grau de utilização desta cobertura de riscos por seguros. No entanto, julga-se oportuno comentar o seguinte:

- a alínea a), que tem a ver com problemas de drenagem local, incluindo, por exemplo, os problemas de drenagem em terraços, equivale a considerar um risco com um período de retorno de cerca de 5 anos para a região de Lisboa, mas já o será inferior a 2 anos em Viseu e a 10 anos em Bragança. De um modo geral corresponderá a um período de retorno de cerca de 5 anos;

- a alínea b) diz respeito a fenómenos muito diferentes e com probabilidades muitos diferentes, talvez oscilando entre os períodos de retorno de poucos anos, em drenos, até aos milhares de anos no rebentamento de barragens;

- a alínea c) diz respeito ao tema que foi tratado com maior minúcia neste documento, e corresponderá a situações muito díspares, desde alojamentos situados em zonas inundáveis todos os anos até às que só serão muito raramente inundáveis.

Todavia existe uma indeterminação das situações nas alíneas b) e c), visto que o transbordamento do leito de cursos de água também pode ser provocado por rebentamento de barragens.

\section{$*$}

A intenção deste texto foi de fazer um diálogo entre as preocupações de desenvolvimento urbano e as preocupações de garantir um razoável risco, procurando explicitar os factores que permitem determinar adequadamente o seu valor. Deve ser também dito que não há nenhuma região da Terra que tenha resolvido completamente o domínio das inundações e seus efeitos. Este problema é tão importante que esta década de 90 foi designada Década Internacional da Redução dos Riscos Naturais. Analogamente, a CEE também tem um programa que analisa estes problemas, o programa EPOCH, 
Programa Europeu Sobre Climatologia e Riscos Naturais.

\section{BIBLIOGRAFIA}

G. T. CHEIAS (1985) - Estudo das causas das cheias na Região de Lisboa. Relatório de Síntese da bacia hidrográfica da Ribeira da Laje. DGO, Lisboa.

ROCHA, J. S.(1978)- A importância dos factores hidráulicos nos planos de ordenamento dos vales inundáveis. $2^{\circ}$ Congresso da Ordem dos Engenheiros, Porto.

ROCHA, J. S. (1987)-Colaboração do LNEC no G. T. das cheias ocorridas em Novembro de 1983 na Área Metropolitana de Lisboa. $1^{\circ}$ relatório. Estudo hidrológico e hidráulico da ribeira da Laje. LNEC, Relatório 197/87 - NHHF, Lisboa.

ROCHA, J. S. e SILVA, A. M.(1987) - Determinaçāo de zonas com risco de inundação para o planeamento urbano. Congresso sobre informática na indústria da construção, LNEC, Lisboa.

SARAIVA, M. G. et al. (1987)-A catástrofe das cheias. O caso da Ribeira da Laje. DGRN, Lisboa.

PORTELA, L. (1990) - As cheias em Portugal. Caracterização das zonas de risco. $1^{\circ}$ relatório: Análise preliminar. Estudo para o SNPC. LNEC, Relatório 142/90 - NHHF, Lisboa. 